\title{
Gêneros Textuais e Agir Docente na Avaliação do ENADE
}

Text Genres and Teaching Acting in Enade’s Evaluation

\author{
Vera Lúcia Lopes CRISTOVÃO* \\ Liliane Mantovani LOPES ${ }^{* *}$
}

Resumo: Este estudo investiga um instrumento de avaliação que tem sido usado na educação inicial de professores - o teste do Exame Nacional de Desempenho dos Estudantes (ENADE) para o curso de Letras (2005 e 2008). Para tanto, identificamos quais gêneros estão presentes no teste, a esfera social a que pertencem e as capacidades de linguagem mobilizadas pelas questões do exame. Nós também analisamos e comparamos a convergência entre o exame do ENADE, as competências mencionadas em um documento oficial para ensino superior e as dimensões que constituem a profissão docente (PLACCO, 2006). Os resultados mostram que o exame demanda gêneros que circulam no cotidiano e valoriza o conhecimento prévio dos alunos bem como suas capacidades de estarem conscientes de problemas sociais em seu país. A dimensão predominante no exame é a críticoreflexivo e a estético e cultural.

Palavras-chave: Gêneros textuais; Ação docente; Avaliação.

Abstract: This study investigates an evaluation tool that has been used for preservice teacher education - the test from the National Exam of Students Performance (ENADE) for Letras course (2005 and 2008).

\footnotetext{
*Pós-doutorado em Linguística Aplicada e Estudos de Linguagem pela PUCSP . Professora Associada do Departamento de Letras Estrangeiras Modernas da Universidade Estadual de Londrina. Contato: veracristovao@yahoo.com ${ }^{* *}$ Mestranda em Estudos da Linguagem na Universidade Estadual de Londrina. $\mathrm{Na}$ época de redação desse artigo e da pesquisa aqui relatada, era aluna de iniciação científica com bolsa do CNPq. Contato: lilianemantovani@yahoo.com.br
} 
In order to do so, we identified the genres which are present in the test, the social sphere they belong to and the language capacities mobilized by the questions. We have also analyzed and compared the convergence among ENADE exam, competences mentioned in an official document for superior teaching and dimensions which constitutes teacher profession (PLACCO, 2006). The results show that the exam demands genres which circulate in everyday life and value students' knowledge background as well as their capacity of being aware of social problems in their country. The predominant dimensions in the exam are critical-reflective and aesthetical and cultural.

Key-words: Text genres; Teaching acting; Evaluation.

\section{Introdução}

A crescente preocupação com a formação do profissional de Letras e o grande número de egressos a todo ano no mercado de trabalho exigem uma ampla discussão sobre a sua formação para o trabalho docente. Tanto a prática docente na formação inicial (curso de graduação em andamento) quanto a formação continuada propiciam oportunidades para desenvolvimento profissional. É na prática de ensino que o aluno futuro professor e o professor em exercício podem perceber a realidade de ensino, investigar seus contextos, além de refletir sobre sua própria experiência.

No ensino superior do Brasil, a aprendizagem na educação inicial para professores de língua estrangeira traz consigo uma gama de outros conhecimentos - que não só o linguístico, mas também conhecimentos socioculturais, situacionais e discursivos (CAMARGO, 2007). Além desta variedade de conhecimentos relacionados entre si, é importante ressaltar o(s) contexto(s) de ensino para qual tal aprendizado se volta, indo desde o ensino regular público até aos institutos de idiomas.

Desse modo, buscando promover uma maior compreensão do trabalho do professor, é essencial atentar para o tipo de conhecimento que se exige em sua educação inicial, a forma como este conhecimento é avaliado e sua relevância para o futuro exercício da área profissional escolhida. 
É neste panorama que surgem os instrumentos de avaliação dos domínios constitutivos da formação inicial e da carreira docente. Mais especificamente na formação inicial, as Diretrizes Curriculares para os cursos de Letras (doravante DCCL) ${ }^{1}$ trazem diversas competências esperadas. O curso de graduação que embasar seu currículo nesse documento supostamente admite a necessidade do desenvolvimento das competências citadas.

Neste sentido, o presente estudo analisa um instrumento de avaliação utilizado na educação inicial de professores de línguas - as provas do Exame Nacional de Desempenho dos Estudantes (ENADE) para o curso de Letras (2005 e 2008). Para isso, são identificados os gêneros textuais presentes bem como sua relação com suas respectivas esferas (contexto de produção) e capacidades de linguagem envolvidas. Além disso, são propostas a análise das dimensões constitutivas do gênero profissional docente e a comparação destes aspectos mencionados com as competências propostas no documento oficial que rege o ensino superior do curso específico, as DCCL.

Este artigo está organizado em três partes. A primeira parte apresenta os pressupostos teóricos que embasaram o estudo: o Interacionismo Sociodiscursivo (ISD) e o agir docente. A segunda parte traz a metodologia, com a descrição das características que compõem as duas provas analisadas. Em seguida, propõe-se a discussão das análises dos conteúdos encontrados em tais instrumentos de avaliação.

\section{Fundamentação Teórica}

\subsection{Armações e lentes}

No quadro recente de pesquisas sobre o trabalho do professor, o ISD tem se ocupado sobremaneira de questões pertinentes à profissão docente no que tange às características desse métier e o papel das diferentes instâncias sociais envolvidas na atividade educacional. Dessa

${ }^{1}$ Diretrizes Curriculares - Cursos de Graduação estão disponíveis em: < http: $/ /$ portal.mec.gov.br/index.php?option $=$ com_content\&view $=$ article\&id $=$ $12991>$. 
forma, seu aparato teórico-metodológico pode ser utilizado para pesquisas que busquem melhor compreender de que maneira se (re)configura o trabalho docente. Para tanto, o ISD (BRONCKART, 2006), considerado uma "ciência do humano", entende a linguagem como essencial para o desenvolvimento humano. É ela que organiza e regula as interações e as atividades. Assim Bronckart define linguagem como:

[...] meio de expressão de processos que seriam estritamente psicológicos (percepção, cognição, sentimentos, emoções) [...] é, na realidade, o instrumento fundador e organizador desses processos, em suas dimensões especificamente humanas. [...] nosso trabalho filia-se a uma abordagem global e tendencialmente unificada do funcionamento psicológico, que toma como unidades de análise a linguagem, as condutas ativas (ou o "agir") e o pensamento consciente. (BRONCKART, 2006, p. 122 - grifos do autor)

Estudos recentes embasados nos pressupostos teóricos do ISD mostram a importância do uso da linguagem em atividades coletivas (BRONCKART, 1999). Com recorrentes mudanças no contexto sóciohistórico que envolve os actantes ${ }^{2}$ nessas atividades, mudanças significativas também são observadas na linguagem. Como todas as produções humanas possuem um caráter histórico (MARX, 1984; VYGOSTKY, 1994), nossas ações estão intimamente relacionadas às atividades de linguagem socialmente construídas. E é por meio dos diversos gêneros textuais que temos a capacidade de organizá-las e desenvolvê-las.

As atividades de linguagem realizadas em práticas sociais são consideradas, por sua vez, como os maiores instrumentos do desenvolvimento humano. Estas atividades constroem ações de

${ }^{2}$ No quadro do ISD, o termo actante é usado para designar qualquer pessoa implicada em um determinado agir. O termo ator é usado quando esse actante tem capacidades, motivos e intenções para o agir representado nos textos e o termo agente é usado para quando essas propriedades não são atribuídas ao actante. 
linguagem que se materializam em textos constituídos por tipos de discurso, expressos por meio de formas linguísticas, relativamente estáveis, a saber: discurso interativo, teórico, relato interativo e narração (BRONCKART, 2006).

Portanto, na abordagem proposta, pretende-se investigar o trabalho com gêneros, que, segundo Matêncio (2008, p. 194):

[...] são compreendidos [...] como artefatos social e individualmente construídos, com base nos quais os sujeitos projetam os papéis sociais e comunicativos, as motivações e intenções, o espaço e o tempo da interação, e textualizam.

A mesma autora concebe a necessidade de se considerar o gênero, nas práticas de educação inicial, como um "instrumento" de vinculação entre a ação de linguagem do sujeito e as práticas sociais de interação. Diante de um evento de interação, o indivíduo, pois, organiza suas ações de linguagem de modo a confrontar a nova demanda e, assim, produz certo equilíbrio na hora de lidar com os recursos semióticos de textualização (MATÊNCIO, 2008). Mais uma vez, conclui-se então, que gêneros não devem ser ensinados, mas sim aprendidos (em eventos de socialização).

Para a pesquisadora, o trabalho com os gêneros acadêmicocientíficos e didáticos na formação de professores é de extrema importância, já que o estudante é levado a compreender conceitos gerais e técnico-científicos, registra seu processo de formação e se apropria de formas de difusão de conhecimento.

Muitas destas atividades envolvem textualização, retextualização, análise linguageira, reescrita e revisão. Assim, dependendo do procedimento adotado e da tarefa objetivada, o professor é levado a redimensionar diferentes saberes e representações. Entre as atividades acima citadas, as de textualização, reescrita e revisão estão ligadas à construção de habilidades linguageiras e só estabelecem relação com as capacidades discursivas quando seu foco, o saber dizer, é vinculado ao saber fazer.

Por isso, é importante que o professor em formação tenha acesso a esse tipo de atividade (saber dizer vinculado ao saberfazer) de diferentes domínios discursivos, pois o foco em somente um deles não promove 
a autonomia esperada do professor. Além da construção de uma identidade linguística, espera-se que o profissional seja capaz de usar a linguagem como instrumento para agir no processo de ensinoaprendizagem.

Ainda segundo a mesma corrente do ISD, um texto, isto é, o material empírico pelo qual os gêneros de diferentes esferas se realizam, somente pode ser compreendido em uma determinada situação de interação e suas práticas de linguagem serão realizadas por meio de suas respectivas capacidades de linguagem (DOLZ; SCHNEUWLY, 1998; 2004).

As capacidades de linguagem são apresentadas por Dolz, Pasquier e Bronckart (1993, p. 30) como "aptidões requeridas para a realização de um texto numa situação de interação determinada”. Elas seriam de três tipos: capacidade de ação, capacidade discursiva e capacidade linguístico-discursiva. A capacidade de ação se constitui pela habilidade em construir conhecimentos e/ou representações que um indivíduo constrói sobre o contexto de produção de um texto, o que pode contribuir para seu reconhecimento do gênero e sua adequação à situação de comunicação. Já a capacidade discursiva se constitui pela habilidade em mobilizar conhecimentos e/ou representações que um indivíduo constrói sobre a organização do conteúdo em um texto e sua apresentação.

Finalmente, a capacidade linguístico-discursiva se constitui pela habilidade em construir conhecimentos e/ou representações que um indivíduo constrói sobre as operações e os recursos de linguagem necessários para a produção ou compreensão de um texto.

Desse modo, considerando a importância do papel da linguagem na construção de tais ações, uma abordagem de ensino baseada no quadro teórico-metodológico do ISD pode proporcionar oportunidades de desenvolvimento do pensamento consciente (do aluno), além da transformação de seu próprio ambiente e do ambiente social (CRISTOVÃO, 2008).

Considerando-se o quadro de pesquisas mais recentes do ISD, encontramos a adoção do conceito de trabalho do professor e partimos do pressuposto que as representações construídas sobre esse trabalho podem ser reveladas nos textos que avaliam o trabalho/o saber/o agir do aluno futuro profissional como professor. 
O processo de educação inicial contempla a avaliação de conhecimentos necessários para a área profissional escolhida. Essa avaliação demanda instrumentos apropriados que, neste caso, se constituem também pelos gêneros textuais que compõem as questões do ENADE, procedimento de avaliação do Sistema Nacional de Avaliação da Educação Superior (SINAES). Diante disso, apresentamos um panorama das provas a serem analisadas. Nesse sentido, o efeito retroativo do exame na formação profissional do professor de Letras deve ser considerado para que possa ser avaliada(s) a coerência e/ou discrepância entre a formação oferecida pelas diferentes instituições de ensino superior e a demanda esperada de um órgão educacional federal (o MEC, responsável pelo exame).

Uma vez analisadas as provas com relação aos gêneros textuais presentes e às capacidades de linguagem mobilizadas nas questões, nos propomos a apresentar outro aspecto importante da prática docente, bem como de todo o contexto de ensino: as dimensões do trabalho do professor. Segundo Placco (2006), a principal função do professor é a de formar cidadãos, isto é, promover a inclusão social do aluno, o qual deve ser analisado em sua multiplicidade - cognitiva, contextual e afetiva. Com esse intuito, a formação do professor deve abranger múltiplas dimensões.

Neste sentido, a autora se dispõe a analisar tais dimensões, relacionando-as com a intencionalidade e a consciência tanto do formador quanto do aluno, buscando apresentar o significado de cada uma delas. Também defende a necessidade de se considerar as dimensões no processo de formação de professores, pois, do contrário, nem o próprio sujeito e nem a sua prática escolar apresentarão resultados satisfatórios.

Estas dimensões são vistas como um conjunto atravessado pela ética e intencionalidade do formador e do formando e para adquirirem sentido não podem ser concebidas separadamente, mas sim dialeticamente em suas relações umas com as outras. Portanto, admitese que o desenvolvimento do sujeito se dá em múltiplas dimensões, mesmo quando o professor não o propicie propositalmente.

Por outro lado, se este desenvolvimento for proposto intencional e conscientemente, o processo formativo será construído com base em sentidos e significados que culminarão em uma aprendizagem efetiva, um passo a mais para a constituição do indivíduo. 
Primeiramente, foram propostas três dimensões (técnica, humano-interacional e política) que depois se desdobraram em técnica ou técnico-científica, humano-interacional, política, da formação continuada, do trabalho coletivo, dos saberes para ensinar, críticoreflexiva, avaliativa, estética, cultural e ética. Todas estas áreas fazem parte da totalidade do ser humano, e trata-se de um assunto difícil de ser lidado, lembrando que ocorrem simultaneamente e apresentam determinados destaques conforme a sua prática.

A dimensão técnica ou técnico-científica abrange os conhecimentos técnico-científicos da área de atuação do professor (ou seja, o domínio do uso da língua) aliados às práticas de ensino, isto é, à capacidade do aluno futuro professor transpor seu conhecimento (de conteúdos diversos), através da articulação com outros saberes, à uma prática efetiva de ensino-aprendizagem e promover o movimento contínuo entre teoria e prática, o que supostamente está presente na formação do professor de inglês.

A dimensão avaliativa trata de um conhecimento mais específico, isto é, conhecimento da prática pedagógica e questões relacionadas ao contexto de trabalho do docente, como, por exemplo, o sistema empregado pela escola em que trabalha. Portanto, diz respeito às bases (teóricas) e fundamentos utilizados em seu exercício profissional - de pesquisa, análises e propostas de resultados - e à apreensão dos diversos contextos interculturais.

A dimensão da formação continuada abrange o interesse e a motivação do profissional pela busca de um constante aperfeiçoamento de sua prática, o que pode variar segundo a exigência do mercado de trabalho. Mesmo depois de formado, é essencial que o profissional continue atualizado, pesquisando sobre sua área de trabalho, seus alunos e a sociedade atual para que, assim, obtenha meios diversos para melhorar seu exercício em sala de aula.

A dimensão dos saberes para ensinar engloba o conhecimento que o professor possui sobre os objetos do processo de ensinoaprendizagem e a forma como são colocados em prática, ou seja, o uso de recursos didáticos em sala de aula, métodos e abordagens. Desse modo, o professor é capaz de perceber as reais necessidades dos alunos por meio do conhecimento de suas experiências e capacidades e poderá adaptar seus procedimentos didáticos de forma útil e eficaz para atender esta demanda. 
A dimensão do trabalho coletivo diz respeito ao trabalho em cooperação, ou seja, engloba a transdisciplinaridade através de projetos desenvolvidos na interação com outros profissionais, a fim de formar um aluno-cidadão. Para que isso ocorra, é importante que o contexto docente permita essa interação e crie uma iniciativa coletiva para a construção de projetos político-pedagógicos, institucionais e até mesmo pessoais.

A dimensão crítico-reflexiva envolve a capacidade do profissional de conhecer seus processos cognitivos bem como de autorregulá-los. Propõe-se como atividade reflexiva um pensamento crítico de nossas crenças e valores que nos faça repensar os fundamentos e resultados de nossas ações, tanto na vida profissional como pessoal.

$\mathrm{Na}$ dimensão estética e cultural, consideram-se as experiências estéticas e culturais da formação do professor e a ação de promovêlas nos alunos. Para ampliar esta diversidade de experiências e contatos com diferentes formas de cultura, é necessário que, em sua formação, o profissional se aproxime de sua cultura e também da cultura do outro e consiga incitar questões de identidade e de cidadania em seu aluno.

\subsection{Objeto de nossas lentes: as provas do ENADE}

O Exame Nacional de Desempenho dos Estudantes (ENADE) é um exame aplicado pelo Ministério da Educação (MEC) de caráter curricular obrigatório dos cursos de graduação, sendo parte integrante do Sistema Nacional de Avaliação da Educação Superior (SINAES) e que busca avaliar o desempenho acadêmico dos estudantes em relação aos conteúdos programáticos previstos pelas Diretrizes Curriculares de cada curso, bem como as habilidades necessárias ao aprofundamento da formação, e o nível de atualização dos estudantes com relação à realidade brasileira e mundial.

Para isso, é aplicado em período trienal aos estudantes de todos os cursos de graduação, ao final do primeiro (ingressantes) e último (concluintes) anos do curso, sendo admitida a utilização de amostras como meio de levantar o perfil dos estudantes para uma melhor compreensão dos resultados - não somente pelos professores, mas, também, por técnicos, dirigentes e autoridades educacionais. 
Além disso, a participação na prova, que tem duração de 4 (quatro) horas, é uma condição indispensável para se obter o histórico escolar, sem o qual o estudante não consegue seu diploma.

Com o objetivo de melhor orientar as Instituições de Ensino Superior (IES) no que diz respeito a reformulações ou ajustes curriculares em seus cursos, os estudantes ingressantes e concluintes são submetidos à mesma prova. A avaliação do desempenho dos alunos é obtida através de conceitos ordenados em 5 (cinco) níveis, conceitos estes estabelecidos por especialistas das diferentes áreas do conhecimento.

Além do domínio de conhecimentos e competências de níveis diversificados para perfis profissionais específicos, espera-se que os graduandos das IES demonstrem compreensão de temas que ultrapassam o seu ambiente próprio de formação, como perspectivas críticas, integradoras e construção de sínteses contextualizadas.

Alguns dos temas abordados estão relacionados a: sociodiversidade; exclusão e minorias; biodiversidade; ecologia; mapas sócio e geopolítico; globalização; arte, cultura e filosofia; políticas públicas; redes sociais e responsabilidade; terceiro setor; relações interpessoais; vida urbana e rural; inclusão/exclusão digital; democracia e cidadania; violência; terrorismo; avanços tecnológicos; relações de trabalho; tecnociência; propriedade intelectual; diferentes mídias e tratamento da informação.

Também são verificadas as capacidades de leitura, interpretação de textos; análise crítica; indução e dedução; relações, comparações e contrastes; valores e consequências; questionamento da realidade; e argumentação por meio de situações-problema, estudos de caso, simulações e interpretação de textos, imagens, gráficos e tabelas.

O Indicador de Diferença entre os Desempenhos Observado e Esperado (IDD) foi elaborado como uma maneira de trazer dados comparativos do desempenho dos estudantes concluintes em relação aos resultados obtidos por outras instituições e é calculado pela diferença entre o desempenho médio do concluinte e o desempenho médio estimado para os concluintes de um determinado curso.

Seu valor varia de 1 (um) a 5 (cinco). Caso a nota atingida seja maior que 3 (três), o curso avaliado supera o resultado médio esperado e, se for menor, os resultados estão aquém da média esperada. Desse 
modo, o IDD de uma IES indica quanto cada curso se destaca em relação à média esperada.

\subsection{Alvo das lentes: descrição das competências sugeridas nas Diretrizes Curriculares}

As Diretrizes Curriculares para o Curso de Letras (DCCL) propõem que o estudante de graduação do curso de Letras, com habilitação em Língua Materna (LM) ou em Língua Estrangeira (LE), nas modalidades de Bacharelado ou de Licenciatura, deve ser identificado por múltiplas competências e habilidades adquiridas durante sua formação acadêmica (convencional, teórica e prática, ou fora dela).

Com o objetivo de formar profissionais que demandem o domínio da língua(s) estudada(s) e sua(s) respectiva(s) cultura(s) para atuar como professores, pesquisadores, críticos literários, tradutores, intérpretes, revisores de textos, roteiristas, secretários, assessores culturais, entre outras atividades, o curso de Letras deve contribuir para o desenvolvimento das seguintes competências e habilidades:

- domínio do uso da língua portuguesa ou de uma língua estrangeira, nas suas manifestações oral e escrita, em termos de recepção e produção de textos;

- reflexão analítica e crítica sobre a linguagem como fenômeno psicológico, educacional, social, histórico, cultural, político e ideológico;

- visão crítica das perspectivas teóricas adotadas nas investigações linguísticas e literárias, que fundamentam sua formação profissional;

- preparação profissional atualizada, de acordo com a dinâmica do mercado de trabalho;

- percepção de diferentes contextos interculturais;

- utilização dos recursos da informática;

- domínio dos conteúdos básicos que são objeto dos processos de ensino e aprendizagem no ensino fundamental e médio;

- domínio dos métodos e técnicas pedagógicas que permitam a transposição dos conhecimentos para os diferentes níveis de ensino (BRASIL, 2001, p. 30). 
O resultado deste processo visa à formação do profissional que, além da base específica consolidada, esteja apto a atuar, interdisciplinarmente, em áreas afins. Espera-se também que seja capaz de resolver problemas, tomar decisões, trabalhar em equipe e comunicar-se dentro da multidisciplinaridade dos diversos saberes que compõem a formação universitária em Letras.

Além disso, o profissional de Letras deve manter um compromisso com a ética; com a responsabilidade social e educacional; com as consequências de sua atuação e desenvolvimento profissional; ampliar o senso crítico necessário para compreender a importância da busca permanente da educação continuada.

\section{Metodologia}

A análise desta pesquisa esteve centrada nas provas do ENADE, um dos instrumentos de avaliação do SINAES, como já dito anteriormente.

Como se propõe a medir o desempenho dos alunos no início e no final do curso, o ENADE tem a possibilidade de avaliar a aprendizagem durante o curso, dando um peso maior às competências profissionais e à formação geral, com ênfase nos temas transversais. Além disso, diz-se capaz de identificar as competências desenvolvidas pelos alunos ao longo de 3 (três) anos de escolarização superior.

\subsection{Descrição das provas do ENADE}

A prova do ENADE 2005 é composta por 40 (quarenta) questões, sendo 10 (dez) delas de Formação Geral (7 (sete) de múltipla escolha e 3 (três) discursivas), comum aos cursos de todas as áreas, e 30 (trinta) de conhecimentos específicos relacionados à área de Letras (25 (vinte e cinco) de múltipla escolha e 5 (cinco) discursivas). As áreas de formação são divididas em: Licenciatura em Língua Portuguesa, Licenciatura em Língua Estrangeira e Bacharelado.

O peso da parte de Formação Geral das questões alternativas corresponde a 55\% (cinquenta e cinco por cento) e das discursivas a $45 \%$ (quarenta e cinco por cento). Já na parte de Componente Específico, o peso das questões alternativas corresponde a 70\% (setenta por cento) e das discursivas a 30\% (trinta por cento) do valor da prova. 
Além disso, são aplicados dois questionários aos estudantes: o primeiro, antes da prova (socioeconômico); e o segundo, ao final da prova (de percepção sobre a prova). Também é aplicado um questionário ao coordenador do curso, no qual se pedem suas impressões sobre o projeto pedagógico e as condições gerais de ensino de seu curso.

A prova do ENADE 2008 avaliou o componente de Formação Geral comum aos cursos de todas as áreas e um componente específico da área de Letras. A parte de Formação Geral foi composta por 8 (oito) questões de múltipla escolha e 2 (duas) discursivas. Já o Componente Específico foi formado por 27 (vinte e sete) questões de múltipla escolha e 3 (três) discursivas, envolvendo situações-problema e estudos de casos.

Assim, o peso de cada uma das partes corresponde a $60 \%$ (sessenta por cento - Formação Geral - múltipla escolha) e 40\% (quarenta por cento - Formação Geral - discursivas), 85\% (oitenta e cinco por cento - Componente Específico - múltipla escolha) e 25\% (vinte e cinco por cento - Componente Específico - discursivas). A prova de 2008 não foi dividida nas 3 (três) áreas (Licenciatura em Língua Portuguesa; Licenciatura em Língua Estrangeira e Bacharelado), a única divisão foi entre Licenciatura e Bacharelado.

\subsection{Descrição dos procedimentos de análise}

A análise de ambas as provas foram feitas, primeiramente, com base em três categorias: o gênero a qual cada questão pertencia, sua esfera e as capacidades de linguagem envolvidas. Após a obtenção destes dados, propõe-se a identificação das questões quanto às dimensões constituintes (anteriormente descritas), i.e., as dimensões técnica ou técnico-científica, humano-interacional, política, da formação continuada, do trabalho coletivo, dos saberes para ensinar, críticoreflexiva, avaliativa, estética, cultural e ética.

Foram considerados: gênero (configurações das atividades de interação, papel social e comunicativo, organização, estrutura gramatical, vocabulário específico, contexto, layout, registro - formal ou informal), a esfera a qual o gênero pertence (optou-se por classificá-la segundo seu contexto de produção - e não o de circulação - como forma de 
delimitar os possíveis domínios discursivos onde estes gêneros aparecem). Finalmente, quanto às capacidades de linguagem, é elaborado o seguinte quadro explicitando os critérios:

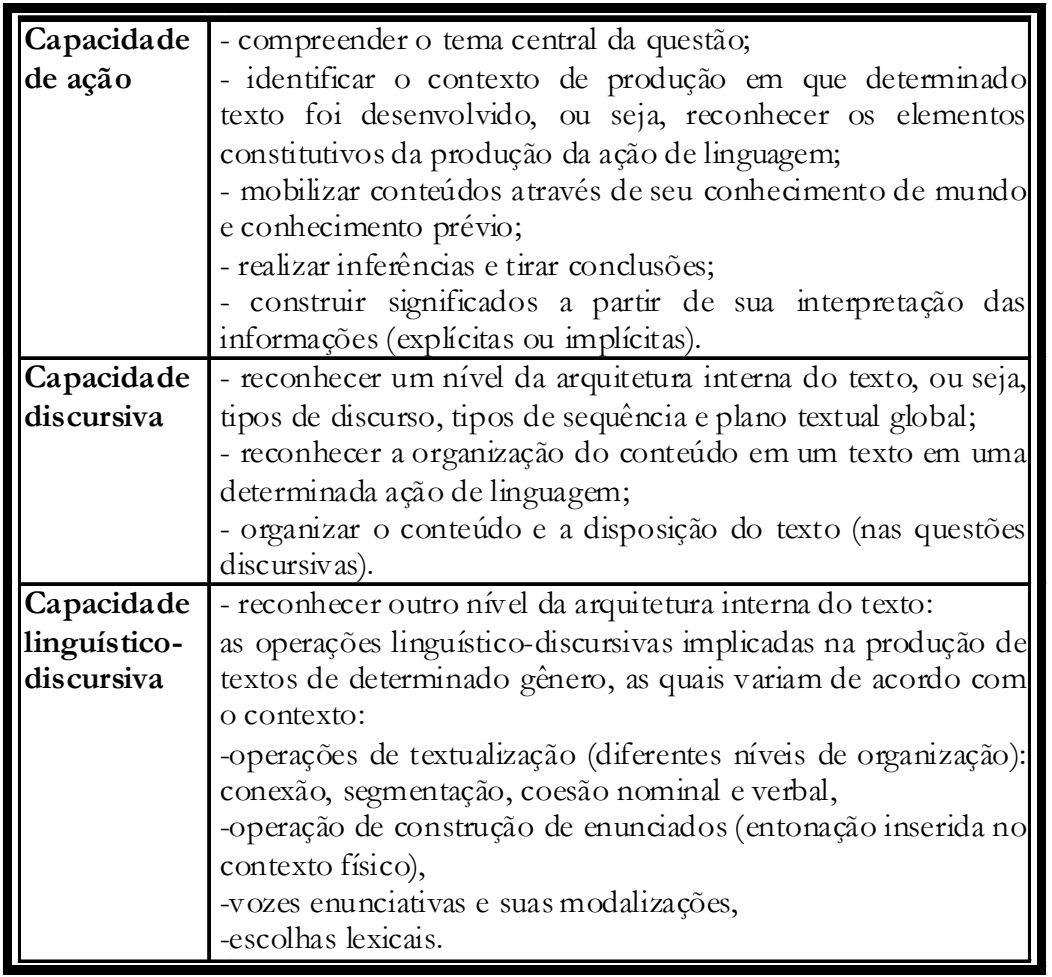

Quadro 1 - Critérios para definição das capacidades de linguagem

As questões que não se enquadraram nessa classificação, foram analisadas quanto a outro tipo de conhecimento exigido como conhecimento léxico-gramatical descontextualizado. Exemplo: 


\section{Questão 5}

Leia o texto e analise os dados lingüísticos que o seguem.

Estar e andar + gerúndio

No período arcaico esses verbos seguidos de gerúndio podem ocorrer semanticamente plenos, com significado lexical etimológico: estar (lat. stare) "estar de pé"; andar (lat. ambitare) "deslocar-se com os pés". $\mathrm{Na}$ documentação arcaica, em muitos contextos, fica-se na dúvida se nas seqüências desses verbos com gerúndio se tem uma locução verbal ou duas orações com um desses verbos como principal e o gerúndio como uma subordinada redurida temporal.

\section{Exemplos:}

1. No dia da sa morte estando os homens bõos da cidade onde el era bispo fazendo gram chanto sobre el...

[No dia da sua morte, estando de pé os homens bons da cidade onde ele era bispo, fazendo... ou No dia de sua morte, estando os homens bons da cidade onde ele era bispo fazendo...]

2. Andava per muitas cidades e per muitas vilas e per muitos castelos e pelas ruas e pelas casas dos homẽ dizendo muitas santas paravoas.

[Caminhava por muitas cidades e por muitas vilas e por muitos castelos e pelas ruas e pelas casas dos homens dizendo... ou Estava dizendo por muitas cidades e por muitas vilas e por muitos castelos e pelas ruas e pelas casas dos homens...]

(Adaptado de R. V. Mattos e Silva, O português arcaico)

A dúvida sobre o Português Arcaico, explicitada por Mattos e Silva, mantém-se nas construções com estar e com andar seguidos de gerúndio do Português Contemporâneo do Brasil? Explique e dê um exemplo de construção com cada um desses verbos para confirmar sua hipótese.

(Valor: 10,0 pontos)

Quadro 2 - Questão 5 (ENADE 2005 - discursivas para todas as áreas)

Quanto à relação entre o conteúdo das provas e as dimensões e competências, fizemos a seguinte associação: 


\begin{tabular}{|c|c|c|c|c|}
\hline \multirow[t]{2}{*}{$\begin{array}{c}\text { Competências das } \\
\text { DCL }\end{array}$} & \multirow[t]{2}{*}{ Dimensões } & \multicolumn{3}{|c|}{$\begin{array}{l}\text { Competências e dimensões } \\
\text { presentes no Enade } 2005 \text { e } \\
2008\end{array}$} \\
\hline & & ausente & parcial & presente \\
\hline $\begin{array}{l}\text { Domínio do uso da } \\
\text { LP ou de uma LE }\end{array}$ & Técnico-científica & & & \\
\hline $\begin{array}{l}\text { Reflexão analítica e } \\
\text { crítica sobre a } \\
\text { linguagem }\end{array}$ & $\begin{array}{l}\text { Avaliativa, crítico- } \\
\text { reflexiva, estética e } \\
\text { cultural }\end{array}$ & & & \\
\hline $\begin{array}{c}\text { Visão crítica das } \\
\text { perspectivas teóricas } \\
\text { (lingüísticas e } \\
\text { literárias) } \\
\end{array}$ & $\begin{array}{l}\text { Avaliativa, crítico- } \\
\text { reflexiva ética e } \\
\text { política }\end{array}$ & & & \\
\hline $\begin{array}{c}\text { Preparação } \\
\text { profissional } \\
\text { atualizada }\end{array}$ & $\begin{array}{l}\text { Da formação } \\
\text { continuada }\end{array}$ & & & \\
\hline $\begin{array}{c}\text { Percepção de } \\
\text { diferentes contextos } \\
\text { interculturais; } \\
\end{array}$ & $\begin{array}{c}\text { Avaliativa, dos } \\
\text { saberes para ensinar }\end{array}$ & & & \\
\hline $\begin{array}{l}\text { Utilização dos } \\
\text { recursos de } \\
\text { informática; }\end{array}$ & $\begin{array}{l}\text { Dos saberes para } \\
\text { ensinar, técnico- } \\
\text { científica }\end{array}$ & & & \\
\hline $\begin{array}{l}\text { Domínio dos } \\
\text { conteúdos básicos }\end{array}$ & $\begin{array}{l}\text { Dos saberes para } \\
\text { ensinar, técnico- } \\
\text { científica, ética e } \\
\text { política }\end{array}$ & & & \\
\hline $\begin{array}{l}\text { Domínio dos } \\
\text { métodos e técnicas } \\
\text { pedagógicas }\end{array}$ & $\begin{array}{l}\text { Dos saberes para } \\
\text { ensinar, técnico- } \\
\text { científica, do } \\
\text { trabalho coletivo }\end{array}$ & & & \\
\hline
\end{tabular}

Quadro 3 - Relação entre o conteúdo das provas, dimensões e competências

\section{Resultados e discussão}

Nesta parte do artigo, pretende-se exemplificar as questões analisadas anteriormente quanto aos gêneros integrantes das questões, suas respectivas esferas, capacidades de linguagem (ou excepcionalmente, outros conhecimentos exigidos), dimensões e como estes aspectos são abordados. Além disso, foi feita uma avaliação das competências presentes no documento das DCCL e as presentes no 
formulário para o exame do ENADE (2005 e 2008), bem como suas relações com as dimensões da formação e do trabalho do professor.

Primeiramente, no que diz respeito aos gêneros textuais, na parte da Formação Geral (questões alternativas) do ENADE 2005, nota-se a predominância (30\% -trinta por cento) dos gêneros notícia e charge (esferas jornalística e humorística, respectivamente), o que mostra a ênfase na capacidade de o aluno confrontar diferentes pontos de vista, isto é, verificar sua visão crítica acerca de fatos ocorridos no cotidiano e que envolvem questões de cidadania, da vida política e social.

Além disso, a leitura destes gêneros (e, em especial, do gênero notícia) envolve estratégias - como skimming e scanning - de modo a colaborar com uma interpretação crítica e até mesmo na compreensão de suas características estilísticas (tema, layout, estrutura, grau de formalidade, etc.).

Depois de passar por este processo, construir sentidos do texto e de seu meio social, é possível se conscientizar de ações que demandam a interpretação social dos agentes, da ação proposta, de marcas de sujeito (pessoal, impessoal), de uma possível intenção do autor de determinado texto, de pessoas envolvidas, do discurso, etc.. Assim, espera-se contribuir para a formação não apenas de um mero usuário da língua, mas de um usuário crítico da língua.

Para este fim, o estudante deve analisar o tema central do texto, fazer inferências a partir de informações implícitas e de seu conhecimento prévio para assim construir sentido e significado; a capacidade de linguagem utilizada, portanto, é a de ação. Porém, fica em segundo plano a inferência sobre a intenção dos envolvidos no contexto de produção, ou seja, as representações que envolvem as intenções dentro da interação comunicativa (autor ou enunciatários do texto).

$\mathrm{Na}$ modalidade discursiva da mesma parte, observa-se que as três questões que a compõem estão relacionadas com as três capacidades simultaneamente $(\mathrm{CA}+\mathrm{CD}+\mathrm{CLD})$. Outra característica apresentada é em relação ao tema, pois duas delas trazem o tema da degradação do meio ambiente: devastação da Amazônia e o fenômeno do aquecimento global (questões 1 e 3 , respectivamente).

Já na parte da Formação Específica da modalidade alternativa, há predominância do gênero poema, trechos de romance, entrevista oral e 
depoimento (esfera literária, acadêmica e jornalística, respectivamente). Por sua vez, a capacidade priorizada foi a de ação, já que o aluno precisa atentar para a mobilização de conteúdos diversos a fim de construir novos significados.

No componente Específico (alternativa) para os cursos de Licenciatura em Língua Portuguesa, o gênero predominante é o artigo científico (esfera acadêmica) e, como prioridade, a capacidade de ação, em que é necessário levar em conta o contexto de produção de determinado enunciado e a mobilização de conteúdos.

Somente uma questão compõe a parte Específica (discursiva) para Licenciatura em Língua Portuguesa e para Língua Estrangeira. São estes, respectivamente: relato de experiência (pertence à esfera escolar e envolvendo CA) e convite/documento oficial (texto pré-figurativo para o ensino de LE no ensino fundamental) da esfera interpessoal/acadêmica com a mobilização simultânea da CA além da CD. Por fim, as questões discursivas - comuns a todas as áreas - apresentam, sem exceção, o gênero artigo científico, constituinte da esfera acadêmica.

Desta forma, os gêneros presentes na prova de 2005 foram:

\begin{tabular}{|l|l|l|}
\hline$\bullet$ artigo acadêmico & $\bullet$ depoimento & $\bullet$ notícia \\
\hline$\bullet$ artigo científico & $\bullet$ desenho & $\bullet$ pintura \\
\hline$\bullet$ carta-resposta & $\bullet$ documento oficial & $\bullet$ poema \\
\hline$\bullet$ charge & $\bullet$ ensaio & $\bullet$ relato de experiência \\
\hline$\bullet$ comentário & $\bullet \begin{array}{l}\text { entrevista de } \\
\text { emprego }\end{array}$ & $\bullet$ reportagem \\
\hline$\bullet$ conto & $\bullet$ entrevista oral & $\bullet$ resenha \\
\hline$\bullet$ convite & $\bullet$ gráfico & $\bullet$ romance \\
\hline$\bullet$ crítica & $\bullet$ gravura & $\begin{array}{l}\bullet \text { transcrição de um } \\
\text { enunciado }\end{array}$ \\
\hline
\end{tabular}

Quadro 4-Gêneros textuais presentes no ENADE 2005

As esferas, por sua vez, variaram entre: 


\begin{tabular}{||l|l|l|}
\hline - Acadêmica & $\bullet$ Escolar & $\begin{array}{l}\bullet \text { Interpessoal } \\
\text { acadêmica }\end{array}$ \\
\hline$\bullet$ Acadêmica literária & $\bullet$ Humorística & $\bullet$ Jornalística \\
\hline - Artística literária & $\begin{array}{l}\bullet \text { Humorística } \\
\text { jornalística }\end{array}$ & $\bullet$ Literária \\
\hline$\bullet$ Do trabalho & $\bullet$ Humorística virtual & $\bullet$ Política \\
\hline
\end{tabular}

Quadro 5 - Esferas presentes no ENADE 2005

A seguir, o gráfico mostra a porcentagem das capacidades presentes na prova (CA, CD e CLD):

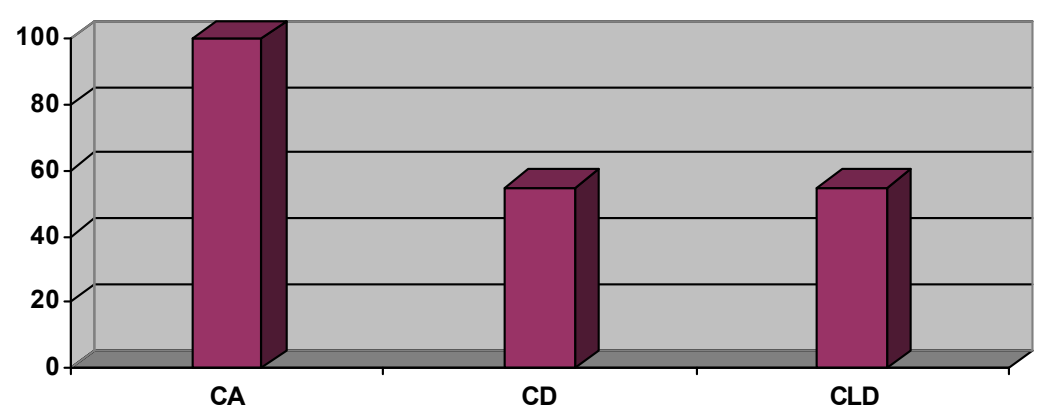

Gráfico 1 - Capacidades de linguagem em porcentagem (ENADE 2005)

Por meio do gráfico acima, percebe-se a enorme predominância da CA no exame. Uma vez que esta capacidade é responsável por mobilizar conteúdos que exigem, simultaneamente, a mobilização do conhecimento prévio e do conhecimento de mundo do aluno, concluise que as questões que envolvem CA apresentam temas relacionados a conhecimentos gerais. Se, por um lado, esta capacidade esteve presente em todas as questões da prova, por outro lado a mobilização destes conhecimentos se deu em relação ao conteúdo, e não necessariamente em relação ao contexto de produção, circulação ou recepção dos gêneros textuais mobilizados no teste. $\mathrm{O}$ conhecimento privilegiado está mais ligado ao conteúdo temático dos gêneros do que seus aspectos sócio-históricos. 
Além disso, com a descrição dos critérios utilizados na definição de tal capacidade (metodologia) e com a interpretação do gráfico em que se percebe sua presença majoritária, infere-se que a maioria das questões do exame é abordada de forma contextualizada. Os textos utilizados como base para interpretação são, em sua maioria, de circulação social.

Vale ressaltar que estas questões em que a CA está presente envolvem, necessariamente, as dimensões crítico-reflexiva e estética e cultural, uma vez que requerem a interpretação como atividade reflexiva e a construção do significado de identidades e cidadania a partir de textos produzidos sob diferentes formas de cultura, respectivamente. Exemplo:

32. Leia a seguinte proposta de Paulo Freire (A importância do ato de ler) sobre a função do professor.

A questão da coerência entre a opção proclamada e a prática é uma das exigências que educadores críticos se fazem a si mesmos. É que sabem muito bem que não é o discurso que ajuiza a prática, mas a prática que ajuíza o discurso. Nem sempre, infelizmente, muitos de nós, educadoras e educadores que proclamamos uma opção democrática, temos uma prática em coerência com nosso discurso avançado. Daí que o nosso discurso, incoerente com a prática, vire puro palavreado.

Considere os trechos transcritos abaixo, adaptados de Pérez Gómez (“A função e a formação do professor/a no ensino para a compreensão: diferentes perspectivas").

I. Perspectiva enciclopédica: de acordo com a concepção de ensino como transmissão de conteúdos da cultura e da aprendizagem como acumulação de conhecimentos; propõe a formação do professor como especialista num ou vários ramos do conhecimento, quanto mais conhecimento ele possua melhor poderá desenvolver sua função de transmissão.

II. Perspectiva técnica: a qualidade do ensino é evidenciada na qualidade dos produtos e na eficácia e economia de sua realização; forma-se o professor como um técnico que domina as aplicações do conhecimento científico produzido por outros e transformado em regras de atuação.

III. Perspectiva de reconstrução social: o professor reflete criticamente sobre a prática cotidiana para compreender tanto as características dos processos de ensino-aprendizagem quanto as do contexto em que o ensino ocorre; a formação do professor pressupõe o ensino como uma prática social saturada de opções de caráter ético cujos valores se 
traduzem coerentemente em procedimentos que facilitem o desenvolvimento emancipador dos que participam do processo.

Contempla a prática pedagógica recomendada por Paulo Freire - o que evitaria a crítica feita pelo pedagogo - APENAS o que se afirma em

(A) I.

(B) III.

(C) I e II.

(D) I e III.

(E) II e III.

Quadro 6 - Questão 32: Componente Específico para Licenciatura em Língua Portuguesa (ENADE 2005)

Um fator comum entre todas as questões discursivas foi a presença simultânea das três capacidades de linguagem, pois todas, sem exceção, fazem uso de textos para deflagrar a produção textual.

Comparando-se as exigências destacadas pela proposta das Diretrizes com as dimensões da formação e do trabalho do professor presentes no ENADE 2005, comprova-se que algumas dimensões foram predominantes e que nem todas as propostas das Diretrizes são cumpridas. Como já citado anteriormente, as dimensões críticoreflexiva e estética e cultural estiveram presentes em todas as questões.

Também foram constatadas, em menor número, as dimensões "técnico-científica" (que mobiliza não só o conhecimento da língua como estrutura, mas também sua transposição), "dos saberes para ensinar” (que envolve o domínio de conteúdos básicos da aprendizagem no ensino fundamental e médio e de práticas pedagógicas pertinentes), "ética e política" (questões relacionadas ao processo educacional e ao compromisso do profissional com a ética e a política) e, em um caso, "da formação continuada" (comprometimento do professor com a prática investigativa para a construção de conhecimento).

Contudo, não foram consideradas as dimensões "do trabalho coletivo" (possibilidade de se desenvolver projetos políticopedagógicos juntamente com a transdisciplinaridade) e "avaliativa" (a qual diz respeito a assuntos específicos da prática pedagógica).

Em contrapartida, a prova do ENADE 2008 apresenta, na parte de Formação Geral, em sua maioria (12,5\% - doze e meio por cento), 
os gêneros artigo e romance (esferas acadêmica e literária, respectivamente). Estas questões pretendem avaliar se o estudante desenvolveu, no processo de formação, domínio da norma culta da língua utilizada (no caso, da língua portuguesa) bem como uma visão crítica das perspectivas teóricas adotadas nas investigações linguísticas e literárias.

Como resultado da presença majoritária destes gêneros, notase a exigência do desenvolvimento de habilidades necessárias para se atingir a competência desejada no desempenho, principalmente pelo gênero acadêmico. O domínio da escrita (língua portuguesa) esteve presente em questões discursivas, porém, assim como ocorreu na prova do ENADE 2005, não foi exigida a compreensão oral em língua portuguesa ou estrangeira. Exemplos:

\section{QUESTÃO 17}

"Ao lermos, se estamos descobrindo a expressão de outrem, estamos também nos revelando, seja para nós mesmos, seja abertamente. Daí por que a troca de idéias nos acrescenta, permite dimensionarmo-nos melhor, esclarecendonos para nós mesmos, lendo nossos interlocutores. Tanto sabia disso Sócrates como o sabe o artista de rua: "conversando também conheço o que é que eu digo".

Recepção e interação na leitura. In: Pensar a leitura: complexidade. Eliana Yunes (Org). Rio de Janeiro: PUCRio; São Paulo: Loyola, 2002, p. 105 (com adaptações).

A partir das reflexões do texto apresentado, assinale a opção correta a respeito da interação texto-leitor.

A A aproximação, no texto, entre o que sabia Sócrates e o que sabe o artista de rua, é incoerente porque os respectivos horizontes de expectativa são diferentes.

B A perspectiva apontada no texto favorece a vivência da leitura como autoconhecimento, em detrimento da leitura como identificação da expressão do outro.

C A leitura como descobrimento pressupõe uma postura pedagógica que reforça a tradição de leitura como confirmação da fala de uma autoridade.

D A interação texto-leitor deve ser evitada, por fugir ao controle do autor e favorecer uma espécie de "vale-tudo interpretativo".

E Para a leitura como descobrimento ser efetiva, é necessária a troca de idéias sobre a leitura; ler com o outro para nos conhecermos.

Quadro 7 - Questão 17: Componente Específico: exemplo de questão do gênero acadêmico (ENADE 2008) 


\section{QUESTÃO 34}

Olhou as cédulas arrumadas na palma, os níqueis e as pratas, suspirou, mordeu os beiços. Nem lhe restava o direito de protestar. Baixava a crista. Se não baixasse, desocuparia a terra, largar-se-ia com a mulher, os filhos pequenos e os cacarecos. Para onde? Hem? Tinha para onde levar a mulher e os meninos? Tinha nada!

(...) Se pudesse mudar-se, gritaria bem alto que o roubavam. Aparentemente resignado, sentia um ódio imenso a qualquer coisa que era ao mesmo tempo a campina seca, o patrão, os soldados e os agentes da prefeitura. Tudo na verdade era contra ele. Estava acostumado, tinha a casca muito grossa, mas às vezes se arreliava. Não havia paciência que suportasse tanta coisa.

Graciliano Ramos. Vidas secas. 106. ${ }^{a}$ ed. São Paulo: Record, 1985, p.96-7.

A leitura do trecho acima do capítulo Contas, do romance Vidas Secas, de Graciliano Ramos, indica que, nessa obra, a relação entre o texto e o contexto de sua produção está concentrada

A na abordagem regionalista e pitoresca do fenômeno ambiental da seca no Nordeste.

$\mathrm{B}$ na representação da riqueza interior de vidas econômica e culturalmente pobres.

C no realismo descritivo, que apresenta pormenores da beleza da paisagem nordestina.

D na atitude engajada do protagonista Fabiano, que se recusa a ser explorado pelo patrão.

E no caráter ufanista da obra, que exalta a força da cultura popular nordestina.

Quadro 8 - Questão 34: Componente específico: exemplo de questão do gênero romance (ENADE 2008)

No total, vinte e três diferentes gêneros estiverem presentes na prova, a saber: 


\begin{tabular}{|l|l|l|}
\hline$\bullet$ artigo & $\bullet$ gráfico & $\bullet$ relato de experiência \\
\hline$\bullet$ cena cinematográfica & $\bullet$ imagem & $\bullet$ reportagem \\
\hline$\bullet$ citação & $\bullet$ legenda & $\bullet$ resenha \\
\hline$\bullet$ crítica & $\bullet$ mapa & $\bullet$ retrato \\
\hline$\bullet$ conto & $\bullet$ notícia & $\bullet$ romance \\
\hline$\bullet$ figura & $\bullet$ pintura & $\begin{array}{l}\bullet \text { texto dramático (peça } \\
\text { teatral) }\end{array}$ \\
\hline$\bullet$ folheto de divulgação & $\bullet$ poema & $\begin{array}{l}\bullet \text { trecho de artigo de } \\
\text { divulgação científica }\end{array}$ \\
\hline$\bullet$ foto & $\bullet$ questão de prova & \\
\hline
\end{tabular}

\section{Quadro 11 - Gêneros textuais presentes no ENADE 2008}

Em relação às capacidades de linguagem, assim como a prova do ano anterior, o ENADE 2008 priorizou a capacidade de ação, que esteve presente em 100\% (cem por cento) das questões da prova. Isso significa que, para o aluno ser capaz de mobilizar esta operação de linguagem, é necessário adaptar sua própria linguagem ao contexto de comunicação em que está inserido.

As questões discursivas (abertas), as quais não exigem nenhum tipo de conhecimento linguístico da Língua Estrangeira, tanto na parte de Formação Geral quanto no Componente Específico, abrangeram mais de uma capacidade, envolvendo temas relacionados à cidadania, contexto escolar e variações linguísticas. Mais uma vez, as três $(\mathrm{CA}+\mathrm{CD}+\mathrm{CLD})$ ocorreram concomitantemente.

A seguir, o gráfico exemplifica as capacidades presentes: 


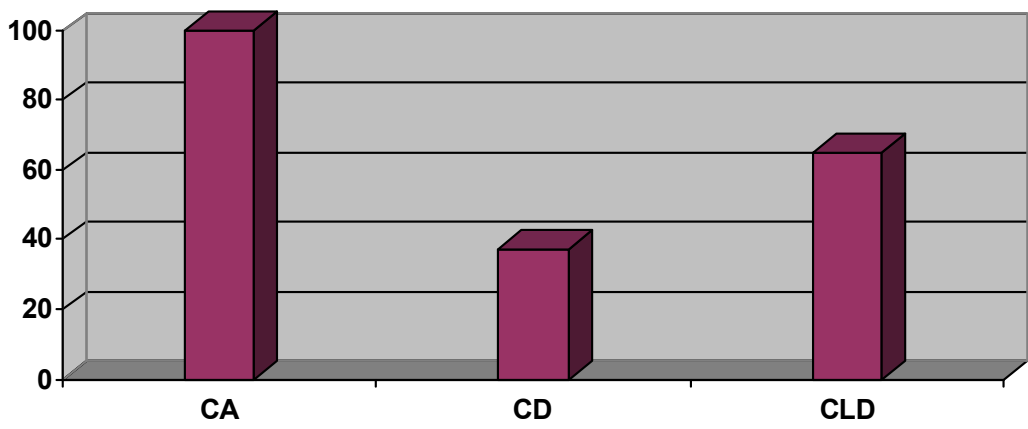

Gráfico 2 - Capacidades de linguagem em porcentagem (ENADE 2008)

Em relação às dimensões do trabalho do professor na prova do ENADE 2008, novamente, nem todas estiveram presentes. As priorizadas foram: "crítico-reflexiva" e "estético-cultural" (presentes em 100\% das questões), "técnico-científica", "dos saberes para ensinar" e, em menor número, "ética e política" e "da formação continuada". Assim como na prova do ano anterior, não foram contempladas as dimensões "do trabalho coletivo" e "avaliativa".

A seguir, explicitamos as competências e dimensões quês estiveram presentes nos ENADE 2005 e 2008, as quais foram classificadas como: 


\begin{tabular}{|c|c|c|c|c|c|}
\hline \multirow{2}{*}{$\begin{array}{c}\text { Competências das } \\
\text { DCL }\end{array}$} & \multirow{2}{*}{ Dimensões } & \multicolumn{4}{|c|}{$\begin{array}{c}\text { Competências e dimensões } \\
\text { presentes no Enade } 2005 \text { e } 2008\end{array}$} \\
\hline & & & ausente & parcial & presente \\
\hline \multirow{2}{*}{$\begin{array}{l}\text { Domínio do uso da LP } \\
\text { ou de uma LE }\end{array}$} & \multirow{2}{*}{$\begin{array}{l}\text { Técnico- } \\
\text { científica }\end{array}$} & 2005 & & $\mathrm{X}$ & \\
\hline & & 2008 & & $X$ & \\
\hline \multirow{2}{*}{$\begin{array}{l}\text { Reflexão analítica e } \\
\text { crítica sobre a } \\
\text { linguagem }\end{array}$} & \multirow{2}{*}{$\begin{array}{l}\text { Crítico- } \\
\text { reflexiva, } \\
\text { estética e } \\
\text { cultural }\end{array}$} & 2005 & & & X \\
\hline & & 2008 & & & X \\
\hline \multirow[b]{2}{*}{$\begin{array}{l}\text { Visão crítica das } \\
\text { perspectivas teóricas } \\
\text { (linguísticas e literárias) }\end{array}$} & \multirow{2}{*}{$\begin{array}{l}\text { Crítico- } \\
\text { reflexiva ética } \\
\text { e política }\end{array}$} & 2005 & & & \\
\hline & & 2008 & & & $\mathrm{X}$ \\
\hline \multirow{2}{*}{$\begin{array}{l}\text { Preparação profissional } \\
\text { atualizada }\end{array}$} & \multirow{2}{*}{$\begin{array}{l}\text { Da formação } \\
\text { continuada }\end{array}$} & 2005 & & $\mathrm{X}$ & \\
\hline & & 2008 & & $X$ & \\
\hline \multirow{2}{*}{$\begin{array}{l}\text { Percepção de diferentes } \\
\text { contextos interculturais; }\end{array}$} & \multirow{2}{*}{$\begin{array}{l}\text { Dos saberes } \\
\text { para ensinar }\end{array}$} & 2005 & & & X \\
\hline & & 2008 & & & X \\
\hline \multirow{2}{*}{$\begin{array}{l}\text { Utilização dos recursos } \\
\text { de informática; }\end{array}$} & \multirow{2}{*}{$\begin{array}{l}\text { Dos saberes } \\
\text { para ensinar, } \\
\text { técnico- } \\
\text { científica }\end{array}$} & 2005 & X & & \\
\hline & & 2008 & & & $\mathrm{X}$ \\
\hline \multirow[b]{2}{*}{$\begin{array}{l}\text { Domínio dos conteúdos } \\
\text { básicos }\end{array}$} & \multirow{2}{*}{$\begin{array}{l}\text { Dos saberes } \\
\text { para ensinar, } \\
\text { técnico- } \\
\text { científica, ética } \\
\text { e política }\end{array}$} & 2005 & & $\mathrm{X}$ & \\
\hline & & 2008 & & $\mathrm{X}$ & \\
\hline \multirow[b]{2}{*}{$\begin{array}{l}\text { Domínio dos métodos } \\
\text { e técnicas pedagógicas }\end{array}$} & \multirow{2}{*}{$\begin{array}{l}\text { Dos saberes } \\
\text { para ensinar, } \\
\text { técnico- } \\
\text { científica, do } \\
\text { trabalho } \\
\text { coletivo }\end{array}$} & 2005 & & $\mathrm{X}$ & \\
\hline & & 2008 & $\mathrm{X}$ & & \\
\hline
\end{tabular}

Quadro 10 - Relação das dimensões e competências das DCCL presentes no ENADE 2005 e 2008 
Como se pode observar no quadro acima, nem todas as oito possíveis dimensões da formação e do trabalho do professor estão presentes em ambos os exames. Além disso, houve mais de uma dimensão relacionada a cada item das DCCL, o que significa que cada proposição do documento envolve, em alguns casos, mais de uma dimensão.

O domínio do uso da LP ou de uma LE (escrita e oral) foi considerada como presente apenas parcialmente em questões discursivas (abertas) nos ENADE 2005 e 2008 pelo fato de não ser exigida, primeiramente, a compreensão oral em língua materna ou estrangeira e, em segundo lugar, por não haver questões que envolvessem diretamente o domínio de uma LE e suas competências. Esta proposição esteve relacionada com a dimensão "técnico-científica" por exigirem basicamente conhecimento gramatical da língua.

O domínio de uma língua estrangeira (no caso, Língua Inglesa) não é comprovado, já que somente uma questão (do tipo dissertativa, para Licenciatura em Língua Estrangeira) aborda o tema relacionado à língua e material didático. Ainda assim, nem o enunciado e nem mesmo a amostra retirada do material didático estão em Língua Inglesa. Também não houve questões que envolvessem tradução de vocábulos ou frases.

Questões que avaliassem a capacidade de reflexão analítica e crítica sobre a linguagem também estiveram presentes nas duas provas e foram relacionadas às dimensões "crítico-reflexiva", "estética e cultural", abordando as diversas visões sobre a linguagem (visão da linguagem como fenômeno psicológico, educacional, social, histórico, cultural, político e ideológico) que estão entrelaçadas.

Também foi exigida uma visão crítica dos alunos em relação às investigações linguísticas e literárias. Mais especificamente, nesta última, as questões trazem temas da Literatura aliados a temas de outras disciplinas, como a Arte. Esta visão crítica contempla as dimensões "crítico-reflexiva" (capacidade de formar opinião crítica) e "ética e política" (questões relacionadas ao processo educacional e ao compromisso do profissional com a ética e a política).

A necessidade de o profissional manter-se atualizado para atender a demanda do mercado de trabalho foi relacionada com a dimensão "da formação continuada" e esteve presente parcialmente nas provas 
em forma de questões abertas que exigiram assuntos relacionados a temas atuais - como o desmatamento e documentos oficiais (ENADE 2005) e a situação dos Ensinos Fundamental e Médio no Brasil (ENADE 2008).

A percepção de diferentes contextos culturais esteve relacionada com a dimensão "dos saberes para ensinar", englobando desde assuntos como o surgimento de novas tecnologias e a prática didática até comparações feitas entre dados contidos em documentos oficiais e a realidade em sala de aula; e a "avaliativa", que remete aos conhecimentos específicos do professor, como questões gramaticais.

A habilidade sobre os recursos de informática não é abordada no ENADE 2005, apenas o tema relacionado à exclusão digital, outro problema enfrentado em sala de aula. Portanto, a habilidade de usar novas tecnologias (como o uso da informática) não é testada. Já no ano de 2008, estão presentes questões discursivas que envolvem as diferentes tecnologias.

O domínio dos conteúdos básicos (os quais são objeto dos processos de ensino e aprendizagem) esteve parcialmente presente nas provas, uma vez que há conteúdos pertencentes à LP, mas faltam conteúdos da LE.

Com relação ao domínio de métodos e de técnicas pedagógicas de diferentes níveis de ensino (fundamental e médio) que visam à transposição de conhecimento para diversos níveis de ensino, somente o trabalho com uma amostra do material didático esteve presente na prova de 2005 (convite de casamento), estando ausente no ano de 2008. Além disso, esta proposição é a única que se relaciona com a dimensão "do trabalho coletivo" por apresentar claramente a interdisciplinaridade: língua e cálculo, pintura e literatura, etc.

Um fator que dificultou a classificação proposta nesta pesquisa (gêneros; esferas; capacidades; dimensões) foi a presença de questões que tiveram a fonte adaptada (quadro 11) ou, ainda, que não apresentam fonte (quadro 12). Neste caso, a definição da esfera a que tal questão pertence foi feita por inferências contextuais, uma vez que o critério para sua classificação esteve baseado no contexto de produção. Exemplos: 


\section{Texto para as questões 11 e 12}

Shirley Paes Leme tem no desenho a alma de sua obra. Os galhos retorcidos e enegrecidos pela fumaça são seus traços a lápis, que ela articula ora em feixes escultóricos, ora em instalações. Produz também delicados desenhos com a sinuosidade da fumaça. Para fazer a peça em homenagem à companhia de dança goiana Quasar, Shirley conta ter se inspirado na grande concentração de energia no espaço necessária para que um espetáculo de dança se realize. "A idéia da coreografia só consegue ser concretizada com movimento porque todos ficam antenados para um trabalho conjunto", diz. A obra de Shirley tem linhas-galhos que se movem em tempos diferentes, impulsionadas por motores ocultos.

Território Expandido. Catálogo da Exposição em homenagem aos indicados ao Prêmio Estadão, 1999, p. 12-3 (com adaptações).

\section{QUESTÃO 11}

A partir da interpretação do texto acima, assinale a opção correta a respeito dos processos de aquisição de língua materna.

A A interpretação dos códigos visuais ocorre por especulação, ao passo que a aquisição das regras gramaticais que permitem o domínio do código lingüístico se dá pela sistematização que se ensina à criança.

B Os erros e desvios da norma na aquisição da língua materna retardam o domínio completo do código; mas, para o domínio dos códigos visuais, os erros constituem o processo de amadurecimento da leitura.

C A apreensão de significados na língua materna se dá, já nas primeiras palavras, pela relação não-ambígua entre significado e significante, ao passo que a indeterminação semântica é inerente aos textos visuais.

D Tanto o domínio da língua materna quanto o de códigos visuais decorrem da inserção do sujeito da linguagem em mundos simbólicos, em uma interação em que a fala do outro imprime significados à própria fala.

E O domínio da língua materna distingue-se do domínio da leitura de textos visuais, entre outros fatores, porque a aprendizagem de signos visuais se dá espacialmente e a interpretação dos signos lingüísticos se dá linearmente.

\section{Quadro 11 - Questão 11: exemplo de questão com fonte adaptada}




\section{QUESTÃO 3}

A exposição aos raios ultravioleta tipo B (UVB) causa queimaduras na pele, que podem ocasionar lesões graves ao longo do tempo. Por essa razão, recomenda-se a utilização de filtros solares, que deixam passar apenas certa fração desses raios, indicada pelo Fator de Proteção Solar (FPS). Por exemplo, um protetor com FPS igual a 10 deixa passar apenas 1/10 (ou seja, retém $90 \%$ ) dos raios UVB. Um protetor que retenha $95 \%$ dos raios UVB possui um FPS igual a

A 95.

B 90.

C 50.

D 20.

E 5.

Quadro 12 - Questão 3: exemplo de questão sem fonte

Ainda houve casos de questões que priorizassem somente parâmetros do plano de ação de linguagem, sinal de que é cobrado do aluno um conhecimento geral sobre o tema, ou seja, privilegia seu conhecimento de mundo, principalmente quando esta capacidade está relacionada à esfera jornalística, outra característica que ignora a especificidade da formação de um profissional de Línguas. Exemplo:

\section{QUESTÃO 3}

3. As ações terroristas cada vez mais se propagam pelo mundo, havendo ataques em várias cidades, em todos os continentes. Nesse contexto, analise a seguinte notícia:

No dia 10 de março de 2005, o Presidente de Governo da Espanba José Luis Rodriguez Zapatero em conferencia sobre o terrorismo, ocorrida em Madri para lembrar os atentados do dia 11 de março de 2004, "assinalou que os espanhöis encheram as ruas em sinal de dor e solidariedade e dois dias depois encheram as urnas, mostrando assim o unico caminho para derrotar o terrorismo: a democracia. Também proclamou que não existe álibi para o assassinato indiscriminado. Zapatero afirmou que não bá politica, nem ideologia, resistência ou luta no terror, só há o vazio da futilidade, a infâmia e a barbárie. Também defendeu a comunidade islâmica, lembrando que não se deve vincular esse fenômeno com nenbuma civilização, cultura ou religião. Por esse motivo apostou na criação pelas Nações Unidas de uma aliança de civilizações para que não se continue ignorando a pobreza extrema, a exclusão social ou os Estados falidos, que constituem, segundo ele, um terreno fértil para o terrorismo".

(MANCEBO, Isabel. Madri fecha conferência sobre terrorismo e relembra os mortos de 11-M. (Adaptado). 
Disponível em:

http://www2.rnw.nl/rnw/pt/atualidade/europa/at050311_onzedemarco? Acesso em Set. 2005)

A principal razão, indicada pelo governante espanhol, para que haja tais iniciativas do terror está explicitada na seguinte afirmação:

(A) O desejo de vingança desencadeia atos de barbárie dos terroristas.

(B) A democracia permite que as organizações terroristas se desenvolvam.

(C) A desigualdade social existente em alguns países alimenta o terrorismo.

(D) $\mathrm{O}$ choque de civilizações aprofunda os abismos culturais entre os países.

(E) A intolerância gera medo e insegurança criando condições para o terrorismo.

Quadro 13 - Questão 3 (ENADE 2005): exemplo de questão que exige $\mathrm{CA}$

\section{Síntese}

O exame parece exigir tipos de gênero de circulação cotidiana, valorizando, assim, o conhecimento de mundo e a capacidade de se manter atualizado em relação às problemáticas sociais do país. Embora todas as questões discursivas envolvessem simultaneamente as três capacidades $(\mathrm{CA}+\mathrm{CD}+\mathrm{CLD})$, isso não foi suficiente para analisar a produção textual dos candidatos em LE, já que as respostas deveriam ser redigidas em língua materna.

Além disso, uma vez que a CA está presente em 100\% (cem por cento) da prova, parece haver uma preocupação em elaborar as questões de forma contextualizada, embora algumas das questões tenham sido classificadas como CA por conta da exigência de certos conteúdos como citado anteriormente nos critérios para definição das capacidades de linguagem - e não necessariamente por trazer situações contextualizadas.

As dimensões "crítico-reflexiva" e "estética e cultural" são as que predominam, ou seja, o exame propõe que o aluno futuro profissional da área de Letras deve ter a capacidade de fazer a atividade reflexiva com base em diferentes tipos de expressão culturais.

O domínio de uma língua estrangeira (no caso, Língua Inglesa) não é comprovado, já que somente uma questão (do tipo dissertativa para Licenciatura em Língua Estrangeira) aborda o tema relacionado 
à língua e material didático. Ainda assim, nem o enunciado e nem mesmo a amostra retirada do material didático estão em Língua Inglesa. Também não houve questões que envolvessem tradução de vocábulos ou frases.

Isso comprova a falta da especificidade de contexto na prova e, consequentemente, além da não inclusão do conteúdo essencial (Língua Inglesa) até mesmo na parte do Componente Específico, os saberes locais de um futuro professor de Línguas são deixados de lado. Portanto, a grande lacuna que se pode perceber é que o exame não comprova o domínio dos alunos em relação à LE.

Outro aspecto relevante diz respeito ao formato da prova. A maioria das questões - principalmente na parte de Formação Geral é apresentada na forma de múltipla escolha, o que pode ser entendido como uma maneira de delimitar, ou, mais precisamente, direcionar o pensamento dos candidatos, isto é, reafirma a concepção errônea de que somente uma interpretação é possível.

\section{Considerações finais}

O presente artigo objetivou analisar um dos instrumentos de avaliação presentes na atividade educacional brasileira - o Exame Nacional de Desempenhos dos Estudantes (ENADE). O foco de tal exame recai sobre a formação profissional do aluno em pré-serviço. Para traçarmos um panorama geral de como se configura o referido teste, identificamos os gêneros textuais presentes nas questões da prova e as esferas de atividade às quais se indexam. Em seguida, procedemos à análise das capacidades de linguagem mobilizadas nas questões do exame, para, finalmente, relacionar tais resultados às questões de educação profissional do professor de línguas (dimensões e competências requeridas desse trabalhador).

Nossas análises evidenciaram a recorrência de gêneros textuais de diferentes esferas enfatizando conhecimentos gerais e/ou de mundo. Esses conhecimentos, por sua vez, implicam na confrontação de diferentes pontos de vista, principalmente dos provenientes das diversas esferas da vida social, o que vai ao encontro da predominância dos gêneros da parte de Formação Geral, supracitados. Ainda, este componente do exame traz as três capacidades de linguagem 
entrelaçadas, exigindo a contextualização tanto da mobilização de conhecimentos e organização como das operações linguísticodiscursivas envolvidas em tal ação.

A lacuna existente na parte da Formação Específica decorre, justamente, da priorização da capacidade de ação em detrimento das outras - diferentemente do que ocorre na parte de Formação Geral. Portanto, ficam pouco exploradas as questões referentes a todo o contexto no qual o gênero está inserido, ou seja, seu viés sócio-histórico. Ressaltamos a necessidade da avaliação específica de LE, do ensino de LE, de possíveis contextos de atuação e da relação com esferas diversas.

\section{Referências}

BRASIL. Ministério da Educação. Conselho Nacional de Educação. Parecer CNE/CES 492/2001. Trata das Diretrizes Curriculares Nacionais dos cursos de Filosofia, Historia, Geografia, Serviço Social, Ciências Sociais, Letras, Biblioteconomia, Arquivologia e Museologia. Diário Oficial da União, Brasília, 9 jul. 2001. Seção 1e, p.50. Disponível em: < http://portal.mec.gov.br/cne/arquivos/pdf/CES0492.pdf>. Acesso em: 28 maio. 2009.

BRONCKART, J.P. Atividade de linguagem, textos e discursos: por um interacionismo sócio-discursivo. Trad. Anna Rachel Machado; Pericles Cunha. São Paulo: Educ, 1999.

. Os gêneros de textos e os tipos de discurso como formatos das interações propiciadoras de desenvolvimento. In: MACHADO, A. R.; MATÊENCIO, M. L. M. (Org). Atividade de linguagem, discurso e desenvolvimento humano. Campinas: Mercado de Letras, 2006. p. 121-160.

- O agir nos discursos: das concepções teóricas às concepções dos trabalhadores. Trad. Anna Rachel Machado, Maria de Lourdes Meirelles Matêncio. Campinas: Mercado de Letras, 2008. 
CAMARGO, G. P. Q. P. Exame Internacional para professores de Inglês: uma análise na perspectiva sócio-interacionista. 2007. 200f. Dissertação (Mestrado em Estudos da Linguagem) - Universidade Estadual de Londrina, Londrina. 2007.

CRISTOVÃO, V. L. L. Aprendendo a planificar o próprio trabalho: gêneros textuais na formação de professores de língua estrangeira. In: ; NASCIMENTO, E. L. (Orgs.). Gêneros textuais: teoria e prática II. Palmas; União da Vitória: Kayguangue, 2005. p. 153-162.

DOLZ, J.; SCHNEUWLY, B. Les capacités orales de apprenants. In: SCHNEUWLY, B.; DOLZ, J. (Orgs.) Pour un enseignement de l'oral: iniciation aux genres formels à l'école. Paris: EFS, 1998. p. 75-89.

; . Gêneros e progressões em expressão oral e escrita: elementos para reflexões sobre uma experiência suíça (francófona). In: SCHNEUWLY, B.; DOLZ, J. (Orgs.) Gêneros orais e escritos na escola. Campinas: Mercado de Letras, 2004. p. 41-70.

LABELLA-SÁNCHEZ, N. As provas de espanhol da UEL, da UEM e da UFPR: capacidades de linguagem e outros conhecimentos exigidos. 2007. 217f. Dissertação (Mestrado em Estudos da Linguagem) Universidade Estadual de Londrina, Londrina. 2007.

MACHADO, A. R. A perspectiva interacionista sociodiscursiva de Bronckart. In: MEURER, J. L.; BONINI, A.; MOTTA-ROTH, D. (Orgs.). Gêneros: teorias, métodos e debates. São Paulo: Parábola, 2005. p. 237-259.

MARX, K. O capital: crítica da economia política. São Paulo: Abril Cultural, 1984.

MATÊNCIO, M. L. M. Gêneros discursivos na formação de professores: reflexões sobre a construção de saberes e o processo de letramento. In: GIL, G.; VIEIRA-ABRAHÃO, M.H. (Orgs). Educação de professores de linguas: os desafios do formador. Campinas: Pontes, 2008. 
PLACCO, V.M.N.S. Perspectivas e dimensões da formação e do trabalho do professor. In: SILVA, A.M.A.M. et al. (Orgs.). Educação formal e não-formal, processos formativos, saberes pedagógicos: desafios para a inclusão social. Recife: ENDIPE, 2006. p. 251-261.

VYGOTSKY, L.S. A formação social da mente: o desenvolvimento dos processos psicológicos superiories. COLE, M. et al. Tradução de José Cipolla Neto, Luis Silveira Menna Barreto, Solando Castro Afeche. 5. ed. São Paulo: Martins Fontes, 1994. 